\title{
Bioelectrical impedance analysis of body composition for the anesthetic induction dose of propofol in older patients
}

\author{
Ana M. Araújo ${ }^{1 *} \mathbb{D}$, Humberto S. Machado ${ }^{1}$, Amílcar C. Falcão ${ }^{2}$ and Patrício Soares-da-Silva ${ }^{3}$
}

\begin{abstract}
Background: Older people are currently the fastest growing segment of the worldwide population. The present study aimed to estimate propofol dose in older patients based on size descriptors measured by bioelectrical impedance analysis (BIA).

Methods: A cross sectional study in adult and older patients with body mass index equal to or lower than $35 \mathrm{~kg} /$ $\mathrm{m}^{2}$ was carried out. BIA and Clinical Frail Scale scoring were performed during pre-operative evaluation. Propofol infusion was started at $2000 \mathrm{mg} / \mathrm{h}$ until loss of consciousness (LOC) which was defined by "loss of eye-lash reflex" and "loss of response to name calling". Total dose of propofol at LOC was recorded. Propofol plasma concentration was measured using gas chromatography/ion trap-mass spectrometry.

Results: Forty patients were enrolled in the study. Total propofol dose required to LOC was lower in Age $\geq 65$ group and a higher plasma propofol concentration was measured in this group. $60 \%$ of old patients were classified as "apparently vulnerable" or "frail" and narrow phase angle values were associated with increasing vulnerability scores. In the Age $\geq 65$ group, the correlation analysis showed that the relationship between propofol dose and total body weight (TBW) scaled by the corresponding phase angle value is stronger than the correlation between propofol dose and TBW or fat free mass (FFM).

Conclusions: This study demonstrates that weight-based reduction of propofol is suitable in older patients; however FFM was not seen to be more effective than TBW to predict the propofol induction dose in these patients. Guiding propofol induction dose according to baseline frailty score should also be considered to estimate individualized dosage profiles. Determination of phase angle value appears to be an easy and reliable tool to assess frailty in older patients.
\end{abstract}

Trial registration: ClinicalTrials.gov Identifier: NCT02713698. Registered on 23 February 2016.

Keywords: Propofol induction dose, Older patients, Phase angle, Frailty

\section{Background}

Older people are currently the fastest growing segment of the worldwide population, and older patients are increasingly submitted to a multiplicity of surgical procedures [1, 2]. Physiologic changes and cognitive dysfunction associated with age, the presence of multiple comorbidities, the use of multiple medications and frailty increase the risk of older patients to adverse postoperative outcomes [1]. As a result,

\footnotetext{
* Correspondence: amfariaaraujo@gmail.com

${ }^{1}$ Serviço de Anestesiologia, Centro Hospitalar Universitário do Porto, Largo Prof. Abel Salazar, 4099-001 Porto, Portugal

Full list of author information is available at the end of the article
}

older people present a larger variation in terms of morbidity and physiological characteristics, which affect the predictability of their response to medications [3]. Variation in frailty likely contributes to this heterogeneity but its effects on pharmacokinetics (PK) and pharmacodynamics (PD) are not yet well understood [3]. Consequently, chronological age is a weak contributing factor of pharmacological response. Age-related physiologic changes per se are not always clinically significant and should not result in the same dose regimen alterations for all chronological old patients [3]. Despite these considerations, current guidelines recommend lower doses of anesthetic agents for

(c) The Author(s). 2019 Open Access This article is distributed under the terms of the Creative Commons Attribution 4.0 International License (http://creativecommons.org/licenses/by/4.0/), which permits unrestricted use, distribution, and 
all chronologically older patients [4-6]. For induction of general anesthesia with propofol, it is generally recommended to decrease propofol dose from $40 \mathrm{mg}$ every $10 \mathrm{~s}(2-2.5 \mathrm{mg} / \mathrm{kg})$ to $20 \mathrm{mg}$ every $10 \mathrm{~s}(1-1.5$ $\mathrm{mg} / \mathrm{kg}$ ) until induction onset [7].

Additionally, bolus dose recommendations for adult non-obese patients are generally made as a function of total body weight (TBW) [8]. Physiologic changes that occur with aging, such as a decrease in total body water, a decrease in lean body weight (LBW) and an increase in body fat, may possibly require the adjustment of propofol doses based on different weight scalars [5, 9]. Mitchell et al. [9] have advocated that LBW may be an alternative choice for drug dose calculation in older patients. Nevertheless, the adequacy of TBW or other size descriptors as predictors of the propofol dose at LOC has not been studied yet in older patients.

Bioelectrical impedance analysis (BIA) is a reference method for the assessment of body composition by measuring resistance and reactance $[9,10]$. Resistance is associated with the quantity of water present in tissues, and reactance is the resistive effect created by the cell membranes and tissue interfaces [11]. Phase angle can be calculated from resistance and reactance [arc-tangent (Reactance/Resistance) ${ }^{*} 180^{\circ} / \pi$ ] and it characterizes the relative effects of fluid (resistance) and cellular membranes (reactance) of the body [11, 12]. Consequently, phase angle has been interpreted as a determining factor of body cell mass, cell membrane integrity, intra and extracellular water distribution and it has also been proposed as a biological sign of cell death $[10,13]$. The phase angle varies with sex, age and body mass index (BMI) but the average value for a healthy individual is generally comprised between 6 and 9 degrees [14].

Phase angle evaluation has been suggested as a prognostic factor in a number of clinical disorders, namely, human immunodeficiency virus infection, liver cirrhosis, chronic obstructive pulmonary disease, hemodialysis, sepsis and lung, breast, colorectal and pancreatic cancer [10]. BIA derived phase angle has also been proposed as an objective measure to recognize frail patients [15]. More recently, Mullie et al. [12] concluded that phase angle is strongly associated with sarcopenia and frailty in older patients, and that it is a promising noninvasive device to assess frailty.

Given the physiologic changes in body composition associated with aging, we planned to determine the appropriate size descriptor, measured by bioelectrical impedance, to estimate propofol induction dose in older patients. We also proposed to assess changes in phase angle values in frail patients. We hypothesized that LBW would be a more appropriate dosing scalar to calculate propofol induction dose in older patients and that old frail patients would require lower doses of propofol during induction of general anesthesia.

\section{Methods}

This study was performed at Centro Hospitalar e Universitário do Porto, Porto, Portugal, after Hospital Review Board and Ethical Committee approvals (IRB: N/REF. ${ }^{a}$ 2015.221(183-DEFI/165-CES) and it provides secondary analyses of data registered at clinicaltrials. gov under the reference NCT02713698 on 23 February 2016.

The main purpose of the research published in clinical trials consisted in the development of a population pharmacokinetic-pharmacodynamic model for propofol when used for induction and maintenance of general anesthesia. Secondarily, sectorial evaluations of the results focusing on the induction and maintenance phases of anesthesia have also been conducted. The first study, planned to assess the ability of body size descriptors to estimate propofol induction dose in obese patients, has already been published [16].

The proposed study is a cross sectional analytical study and it conformed to the requirements of STROBE (Strengthening the reporting of Observational studies in epidemiology) statement. The whole anesthetic procedure was standard except for additional body composition assessment with body composition monitor (BCM, Fresenius Medical Care, Germany) and arterial blood sample. Written informed consent was obtained from all subjects participating in the trial.

\section{Patients}

Adult patients (18-64 years), with ASA (American Society of Anesthesiology) physical status I to III and BMI equal to or lower than $35 \mathrm{~kg} / \mathrm{m}^{2}$ scheduled for elective nose, ear or general surgery and older patients (with 65 or more years), with ASA physical status I to III and BMI equal to or lower than $35 \mathrm{~kg} / \mathrm{m}^{2}$ scheduled for orthopedic or elective nose or ear surgery were included in the study.

Exclusion criteria included the presence of predictive criteria for difficult airway management, dementia, severe hepatic or renal insufficiency, significant hemodynamic instability prior to the surgery and a known allergy to propofol at the time of enrolment. Patients with a pacemaker and pregnant women were also excluded.

Analysis of body composition by bioelectrical impedance BIA was performed by Body Composition Monitor (BCM, Fresenius Medical Care, Germany) during preoperative evaluation in accordance with the manufacturer's recommendations [17]. 
Phase angle values at $50 \mathrm{kHz}$ were registered and standardized values (z-score) were calculated based on reference values generated in a healthy German population [18] according to sex, age and BMI.

The values of resistance and reactance obtained at 50 $\mathrm{kHz}$ were used to estimate fat free mass (FFM) or fat mass (FM) based on specific predictive equations [19]. The equation proposed by Kyle et al. [20] was used in adult patients and the equation proposed by Roubenoff et al. [21] was used in older patients for the assessment of FFM.

$$
\begin{aligned}
\text { FFM }(\text { Kyle equation })= & -4.104+\frac{0,518 \text { Height }^{2}}{\text { Resistance }} \\
& +0.231 \times \text { TBW }+0.130 \\
& \times \text { Reactance }+4.229 \times \text { Sex }
\end{aligned}
$$

$$
\begin{aligned}
& \text { FFM }(\text { Roubenoff equation }) \\
& \begin{aligned}
= & -5.741+\frac{0,4551 \text { Height }^{2}}{\text { Resistance }}+0.1405 \times T B W \\
& +0.0573 \times \text { Reactance }+6.2467 \times \text { Sex }
\end{aligned}
\end{aligned}
$$

\section{Frailty assessment tools}

The 9-point Clinical Frailty Scale (CFS) [22] developed by Geriatric Medicine Research (Dalhousie University, Halifax, Canada) was applied to each patient during preoperative assessment. The CFS was assigned from 1 (very fit) to 9 (terminally ill).

\section{Anesthetic procedure}

All patients were brought to the operating room without premedication. In the operating room, continuous pulse oximetry, electrocardiography, invasive blood pressure and neuromuscular blockade were applied in all patients. The bispectral index (BIS) was monitored using a BIS VISTA ${ }^{\mathrm{m}}$ Bilateral Monitoring System (Covidien, Colorado, US) with a bilateral sensor on the forehead of the patient.

Each subject received a standardized dose of fentanyl $(2 \mu \mathrm{g} / \mathrm{kg})$ or a target controlled infusion of remifentanil (pharmacokinetic model of Minto [23]) was set at $3 \mathrm{ng} / \mathrm{mL}$ before propofol infusion. Propofol infusion (using Orchestra ${ }^{\text {тм }}$ Mobile stand, Fresenius Vial, Brézins, France) was started at $2000 \mathrm{mg} / \mathrm{h}$ (33.3 mg/ min) until LOC, defined by "loss of eye-lash reflex" and "loss of response to name calling". Total dose of propofol at LOC was recorded in all patients. After LOC, rocuronium was administered, propofol infusion rate was guided by the BIS and volume-controlled ventilation was started in all patients. Ventilation parameters setting were: tidal volume $7 \mathrm{ml} / \mathrm{kg}$, respiratory rate $12-14$ cycles per minute to attain normocapnia and PEEP $5 \mathrm{cmH}_{2} \mathrm{O}$.

\section{Quantification of propofol concentration}

Arterial blood samples were collected after LOC and they were centrifuged $(2862 \times \mathrm{g}$ for $5 \mathrm{~min})$ at the end of the surgery. Serum samples were then preserved at $80^{\circ} \mathrm{C}$ until analysis.

Propofol concentration was determined by gas chromatography/ion trap-mass spectrometry (GC/IT-MS) using the method described by Campos et al. [24]. The concentration range for the calibration curve was defined according to the expected serum concentrations $(0.25,0.5,1,2,4,5$ and $10 \mu \mathrm{g} / \mathrm{mL})$.

\section{Sample size}

Literature shows a moderate relationship $\left(r^{2}=0.49\right)$ between propofol induction dose and TBW in adult patients with normal BMI [8]. To the author's knowledge there is no previous study evaluating the relationship between TBW and propofol induction dose in older patients. As a result, sample size considerations were based on association analyses using the Pearson correlation test. To detect a correlation of at least 0.7 between propofol induction dose and TBW a sample of at least 13 subjects was calculated to provide $80 \%$ power and a 0.05 level of significance.

\section{Statistical methodology}

The Shapiro-Wilk test was used to test for the normality of data. Categorical variables are presented as frequency (\%). Continuous data are presented as mean or median (coefficient of variation, CV \%). For comparison between groups, the Student's t-test and the Mann-Whitney-Wilcoxon test were used for continuous variables. The Fisher's exact test was used for categorical variables.

Fisher's exact test was used to estimate the association between CFS and phase angle values: $p$-values, odds ratio (OR) and respective 95\% confidence intervals were obtained.

The relation among propofol dose at LOC, body size descriptors and phase angle was determined by linear regression analysis.

Statistical analyses were performed using GraphPad Prism 8.2.0 software (GraphPad Prism, San Diego, California). A $p$-value $<0.05$ was considered to be statistically significant.

\section{Results}

Twenty adult patients (Age $<65$ group) and twenty older patients (Age $\geq 65$ group) were enrolled for participation in the study from April 2016 to March 2017. Patient's demographics and comorbidity indexes are presented in Table 1. 
Table 1 Patient demographic characteristics and comorbidity indexes

\begin{tabular}{lll}
\hline Variables & Age $<65$ group & Age $\geq 65$ group \\
\hline Age (years) & $42.85(26)^{\mathrm{a}}$ & $77.8(11)^{\mathrm{a}}$ \\
Gender & & \\
Female & $14(70)^{\mathrm{b}}$ & $12(60)^{\mathrm{b}}$ \\
Male & $6(30)^{\mathrm{b}}$ & $8(40)^{\mathrm{b}}$ \\
ASA & & $1(5)^{\mathrm{b}}$ \\
I & $7(35)^{\mathrm{b}}$ & $15(75)^{\mathrm{b}}$ \\
II & $12(60)^{\mathrm{b}}$ & $4(20)^{\mathrm{b}}$ \\
III & $1(5)^{\mathrm{b}}$ & \\
Charlson Comorbidity index & $13(65)^{\mathrm{b}}$ \\
$0-1$ & $18(90)^{\mathrm{b}}$ & $6(30)^{\mathrm{b}}$ \\
$2-3$ & $2(10)^{\mathrm{b}}$ & $1(5)^{\mathrm{b}}$ \\
$4-5$ & 0 &
\end{tabular}

ASA American society of anesthesiology

a Data are present as mean (CV \%)

${ }^{\mathrm{b}}$ Data are presented as frequency (\%)

The body composition of each patient evaluated by BIA is demonstrated in Table 2. The mean percentage of FFM in Age $<65$ and Age $\geq 65$ groups is 33.5 and $30.2 \%$, respectively. There is a good agreement between the LBW values obtained by the Janmahasatian equation $\left(\mathrm{LBW}_{\mathrm{j}}\right)[25]$ and FFM values measured by the BCM in both groups (Fig. 1).

With respect to phase angle values, Fig. 2 shows that lower values were observed in Age $\geq 65$ group in comparison with those observed in the Age $<65$ group. Figure 2 also shows that in Age $\geq 65$ group the median standardized phase angle value (z-score) was lower than expected from a reference healthy population with the same sex, age and BMI.

No relevant changes in heart rate, blood pressure and BIS values were observed following opioid administration.

Table 3 shows that the median absolute dose of propofol to LOC was lower in the Age $\geq 65$ group $(p=0.005)$. Despite the lower propofol induction dose, the mean variation of MAP (mean arterial pressure) was higher in the Age $\geq 65$ group $(p=0.046)$. In this

Table 2 Body composition according to bioelectrical impedance analysis

\begin{tabular}{llll}
\hline Variables & Age $<65$ group & Age $\geq 65$ group & p-value \\
\hline Body mass index $\left(\mathrm{kg} / \mathrm{m}^{2}\right)$ & $25.9(15)$ & $24.3(14)$ & 0.09 \\
Total body weight $(\mathrm{kg})$ & $70.2(21)$ & $63.0(18)$ & 0.18 \\
Fat free mass $(\mathrm{kg})$ & $49.0(23)$ & $41.9(23)$ & 0.04 \\
Fat free mass $(\%)$ & $70.0(10)$ & $66.2(10)$ & 0.09 \\
Fat mass $(\mathrm{kg})$ & $21.1(33)$ & $21.1(24)$ & 0.97 \\
\hline
\end{tabular}

Data are present as mean (CV\%) group, 6 patients showed a variation of MAP values before and after propofol dose higher than $40 \%$. These patients were treated with ephedrine and fluid boluses to return MAP to baseline levels. No changes in heart rate that have required intervention were observed during propofol induction. Table 3 also shows that mean propofol plasma concentration after induction of general anesthesia was higher in the Age $\geq 65$ group.

Clinical frailty scale scores are presented in Table 4. These scores are statistically significant different between groups $(p<0.001)$. Actually, in the Age $\geq 65$ group, $60 \%$ of patients were classified as apparently vulnerable or frail and in the Age $<65$ group all the patients were classified as very fit, well or managing well. Figure 3 shows that lower $\mathrm{z}$-scores are associated with high vulnerability CFS scores. The patients with a CFS score equal to or higher than 4 have been 23 times more often classified with a z-score lower than zero than patients with a CFS score lower than 4 (OR 0.044; 95\% confidence interval 0.0072 to $0.2630 ; p=0.0002$ ).

Regarding the regression analysis, Fig. 4 indicates that propofol dose was similarly related to TBW and FFM in both groups $\left(r^{2}=0.39\right.$ vs 0.36 and $r^{2}=0.48$ vs 0.45$)$. When the TBW is scaled by the corresponding phase angle values, Age $\geq 65$ group shows a stronger relationship than that observed in the Age $<65$ group $\left(r^{2}=0.63\right.$ vs 0.23 ). Figure 4 also compares the propofol doses at LOC with those that would be obtained using a standard bolus approach. Accordingly, the use of a bolus dose of propofol based on TBW ( $1 \mathrm{mg} \cdot \mathrm{TBW})$ would result in inappropriately low doses in some patients of the Age $\geq 65$ group (Fig. 4d). Conversely, the use of the standard dose ( $2 \mathrm{mg} \cdot \mathrm{TBW})$ would be adequate for the Age $<65$ group (Fig. 4a).

\section{Discussion}

In this study, older patients required a lower propofol dose than adult patients to clinical LOC when propofol was administered at a fixed infusion rate. In the Age $\geq 65$ group, the relationship between propofol dose and TBW scaled by the corresponding phase angle values is stronger than the correlation between propofol dose and TBW or FFM.

In the present study, LOC was defined clinically by "loss of eye-lash reflex" and "loss of response to name calling". BIS values were not used to guide propofol dose because of the previously reported delay between clinical recognition of LOC and the decrease in BIS values [26], which may lead to propofol overdosing. The same infusion rate of propofol was adopted in the Age $<65$ and Age $\geq 65$ groups because propofol infusion rate has a critical impact on the dose and time required to induction of general anesthesia [27- 

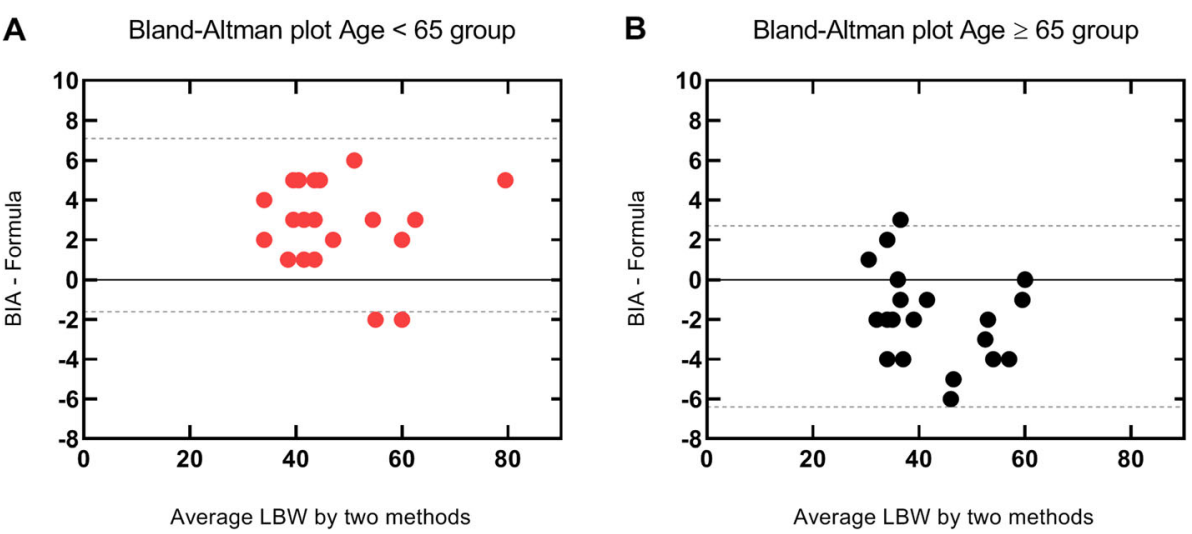

Fig. 1 Bland-Altman plots - Janmahasatian formula vs. body impedance analysis in Age $<65$ group (a) and Age $\geq 65$ group (b). The 95\% limits of agreement are shown as dashed lines. BMI | Body mass index $\left(\mathrm{kg} / \mathrm{m}^{2}\right)$

29]. The use of different infusion rates appear alone to result in different dosing regimens and correlations levels. Additionally, a lower infusion rate $(2000 \mathrm{mg} / \mathrm{h})$ than that exposed in the recommendations $(7200 \mathrm{mg} /$ h) have been selected. According to Chan et al. [30] the use of slower infusion rates allowed more time to observe the specific clinical endpoint of LOC. It has also been published in several studies that the mean MAP variations were lower when slower propofol infusion rates $(2000-3000 \mathrm{mg} / \mathrm{h})$ were used [30-32].

For the fixed infusion rate adopted in the present study, propofol dose to LOC in adult patients was

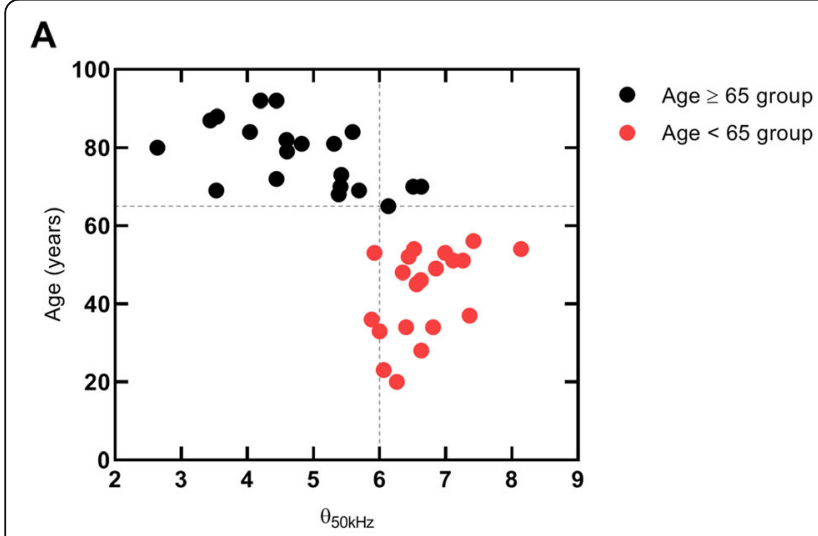

C

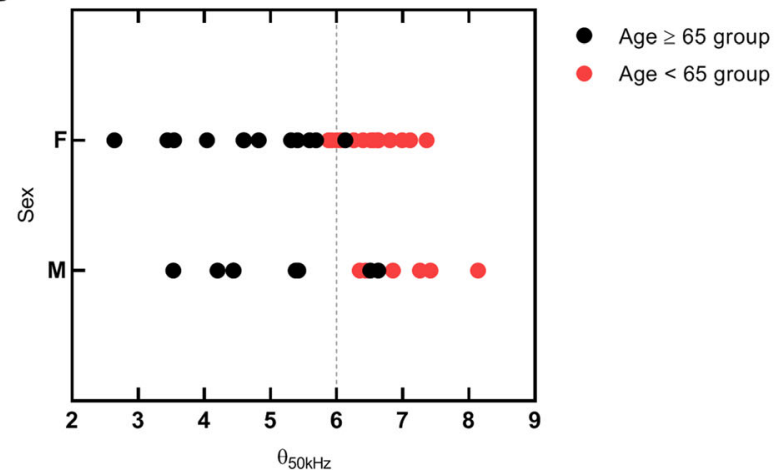

B

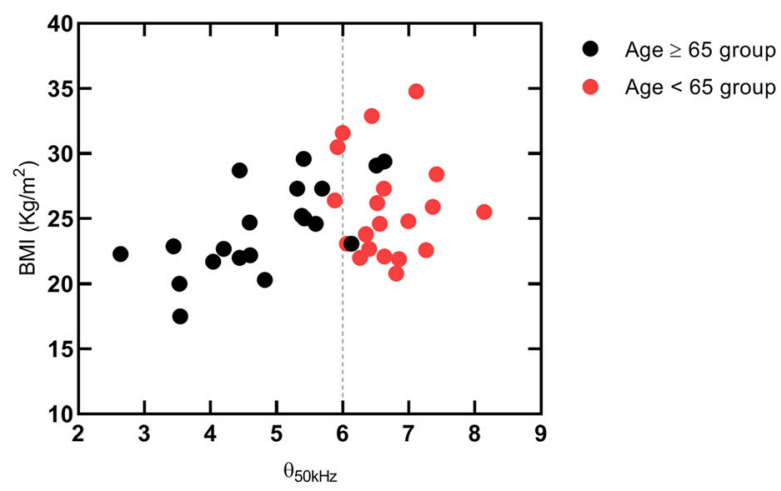

D

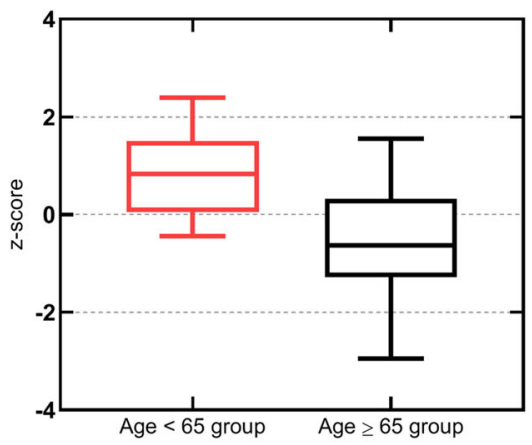

Fig. 2 Phase angle reference values. a, b and $\mathbf{c}$ represent the distribution of phase angle values according to age, BMI and sex. Vertical dashed lines represent lower phase angle reference value in healthy adult population. $\mathbf{d}$ shows the distribution of the standardized phase angle, $z$ score, [z score $=$ (observed phase angle-mean reference phase angle)/SD reference phase angle] for specific age, sex and BMI categories. BMI | Body mass index $\left(\mathrm{kg} / \mathrm{m}^{2}\right)$. F | Female. $\mathrm{M} \mid$ Male. SD | Standard deviation 
Table 3 Propofol dose until loss of consciousness

\begin{tabular}{llll}
\hline Variables & Age $<65$ group & Age $\geq 65$ group & p-value \\
\hline Propofol $(\mathrm{mg})$ & $90(40)^{\mathrm{a}}$ & $68.5(36)^{\mathrm{a}}$ & 0.005 \\
Propofol $(\mathrm{mg} / \mathrm{kg}$ of TBW) & $1.24(30)^{\mathrm{a}}$ & $1.09(25)^{\mathrm{a}}$ & 0.05 \\
Time to LOC $(\mathrm{min})$ & $2.95(1.18)^{\mathrm{b}}$ & $2.17(0.78)^{\mathrm{b}}$ & 0.02 \\
MAP variation $^{\mathrm{d}}(\mathrm{mmHg})$ & $19.62(67)^{\mathrm{c}}$ & $29.04(54)^{\mathrm{c}}$ & 0.05 \\
Plasma [Propofol] $(\mu \mathrm{g} / \mathrm{mL})$ & $3.96(39)^{\mathrm{c}}$ & $7.68(34)^{\mathrm{c}}$ & $<0.001$ \\
Time after LOC $^{\mathrm{e}}(\mathrm{min})$ & $1.6(1.3)^{\mathrm{b}}$ & $1.5(1)^{\mathrm{b}}$ & 0.84 \\
BIS $^{f}$ & $49.5(22)^{\mathrm{a}}$ & $46(27)^{\mathrm{a}}$ & 0.88 \\
\hline
\end{tabular}

LOC Loss of consciousness, MAP Mean arterial pressure, TBW Total body weight

${ }^{\text {aD }}$ Data are presented as median (CV\%)

${ }^{\mathrm{b}}$ Data are presented as mean (SD)

'Data are presented as mean (CV\%)

${ }^{d}$ Variation $=[($ MAP before propofol - MAP after propofol $) /$ MAP

before propofol] ${ }^{*} 100$

${ }^{\mathrm{e}}$ Time after LOC is the time when arterial blood sample was obtained after LOC

${ }^{f}$ Bispectral index value at the time of blood sample collection

similarly correlated with TBW and FFM, as also noticed by Ingrand et al. [8]. Similar considerations were herein observed in the results obtained for the Age $\geq$ 65 group (Fig. 4). These results are in accordance to the results of body composition evaluation by BIA providing that the expecting differences in FFM and FM associated with age [5] were not verified in the present study (Table 2).

By comparing the correlations obtained using TBW as a size descriptor (Table 3), it can also be seen that a lower dose per $\mathrm{kg}$ is required in older patients. This observation is in line with previous literature [7], whereby lower doses of propofol are recommended for older patients. However, the standard bolus dose $(1 \mathrm{mg} / \mathrm{kg}$ based on TBW) may result in inappropriately low doses in some older patients (Fig. 4d).

The results obtained when TBW is scaled by the corresponding phase angle values showed a stronger

Table 4 Clinical frailty scale

\begin{tabular}{|c|c|c|c|}
\hline \multirow{2}{*}{$\begin{array}{l}\text { Age }< \\
65 \\
\text { group }\end{array}$} & \multicolumn{2}{|c|}{ Clinical frailty scale } & \multirow{2}{*}{$\begin{array}{l}\text { Age } \geq \\
65 \\
\text { group }\end{array}$} \\
\hline & Item & Description & \\
\hline $2(10)^{a}$ & 1 & Very fit & 0 \\
\hline $11(55)^{\mathrm{a}}$ & 2 & Well & $2(10)^{a}$ \\
\hline $7(35)^{a}$ & 3 & Managing well & $6\left(30^{) a}\right.$ \\
\hline 0 & 4 & Apparently vulnerable & $7(35)^{a}$ \\
\hline 0 & 5 & Mildly frail & $4(20)^{a}$ \\
\hline 0 & 6 & Moderately frail & $1(5)^{\mathrm{a}}$ \\
\hline 0 & 7 & Severely frail & 0 \\
\hline 0 & 8 & Very severely frail & 0 \\
\hline 0 & 9 & Terminally ill & 0 \\
\hline
\end{tabular}

${ }^{\mathrm{a}}$ Data are presented as frequency (\%) correlation level in the Age $\geq 65$ group (Fig. 4f). This correlation level was not verified in the Age $<65$ group (Fig. 4c). Other authors have previously concluded that BIA derived phase angle can be associated with frailty and that phase angle values can be interpreted as a global marker of health in aging [15]. This fact was noted in the present study, namely on the association observed between standardized phase angle values and CFS scoring in the Age $\geq 65$ group (Fig. 2). Therefore, the differences between the correlation levels obtained for the scalar TBW $\bullet \theta$ in both groups appear to be related to the differences in the registered frail scores.

A small number of studies have previously assessed the effect of frailty as an independent PK predictor to determine thiopental [33] and propofol [34] dose. Additionally, it has been recommended that perioperative analgesia protocols should be individualized in frail patients $[1,3]$.

With respect to propofol plasma levels (Table 2), a higher value was found in older patients, thus corroborating the age-related decrease in volume of distribution and inter-compartmental clearance expected in these patients [5, 35]. Higher propofol plasma levels predispose older patients to cardiovascular side effects associated to propofol. In this study, the higher mean MAP variation was observed in the Age $\geq 65$ group (Table 2). A slow induction has already been recommended for older patients in order to minimize postinduction hypotension [7]. Thus, when infusion rates higher than those adopted in this study are considered, increased MAP variations may be expected. Consequently, since low MAP and deep hypnosis is a predictor of excessive hospital length of stay and post-operative mortality [36], slow titration and monitoring of propofol action is judicious in this group of patients during induction of general anesthesia.

There are potential limitations associated to this study specifically the delay between clinical LOC and blood sample collection. Nevertheless, the average time was not significantly different between groups and the range of plasma concentrations measured ascertained the differences observed in propofol dose to LOC and hemodynamic side effects. Additionally, in this study, each patient received a standardized dose of fentanyl or remifentanil, according to the scheduled surgery. Notwithstanding the synergistic interaction between opioids and propofol for the suppression of purposeful movement to skin incision, the effect of opioids in the absence of a painful stimulus is limited [37]. It was shown by Milne et al. [38] that low target remifentanil concentrations $(<4 \mathrm{ng} / \mathrm{mL})$ have low hypnotic potency and therefore a limited impact on propofol dose requirements when a painful stimuli is not applied. With respect to fentanyl, it has 


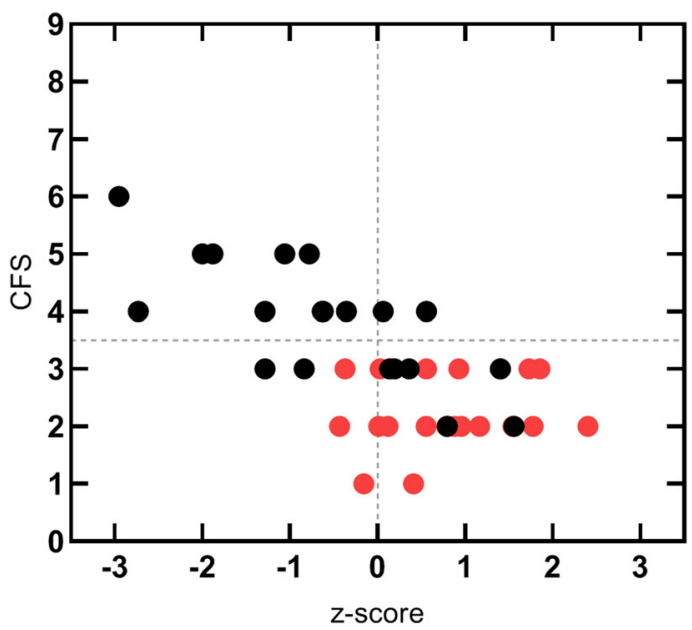

Age $\geq 65$ group

- Age $<65$ group

Fig. 3 Standardized phase angle (z-score) and clinical frail scale scores for each patient. CFS | Clinical frail scale

been concluded that the interaction between fentanyl and propofol for LOC is minor $[39,40]$.

\section{Conclusion}

For the fixed infusion rate of propofol $(2000 \mathrm{mg} / \mathrm{h}) \mathrm{used}$ in the present study, a lower dose of propofol based on
TBW is suitable in older patients when compared to that required for adult patients. Nevertheless, the cumulative declines of physiologic systems and the baseline vulnerability to adverse outcomes specific of frail patients should also be measured to estimate individualized dosage profiles. Determination of phase angle appears to be

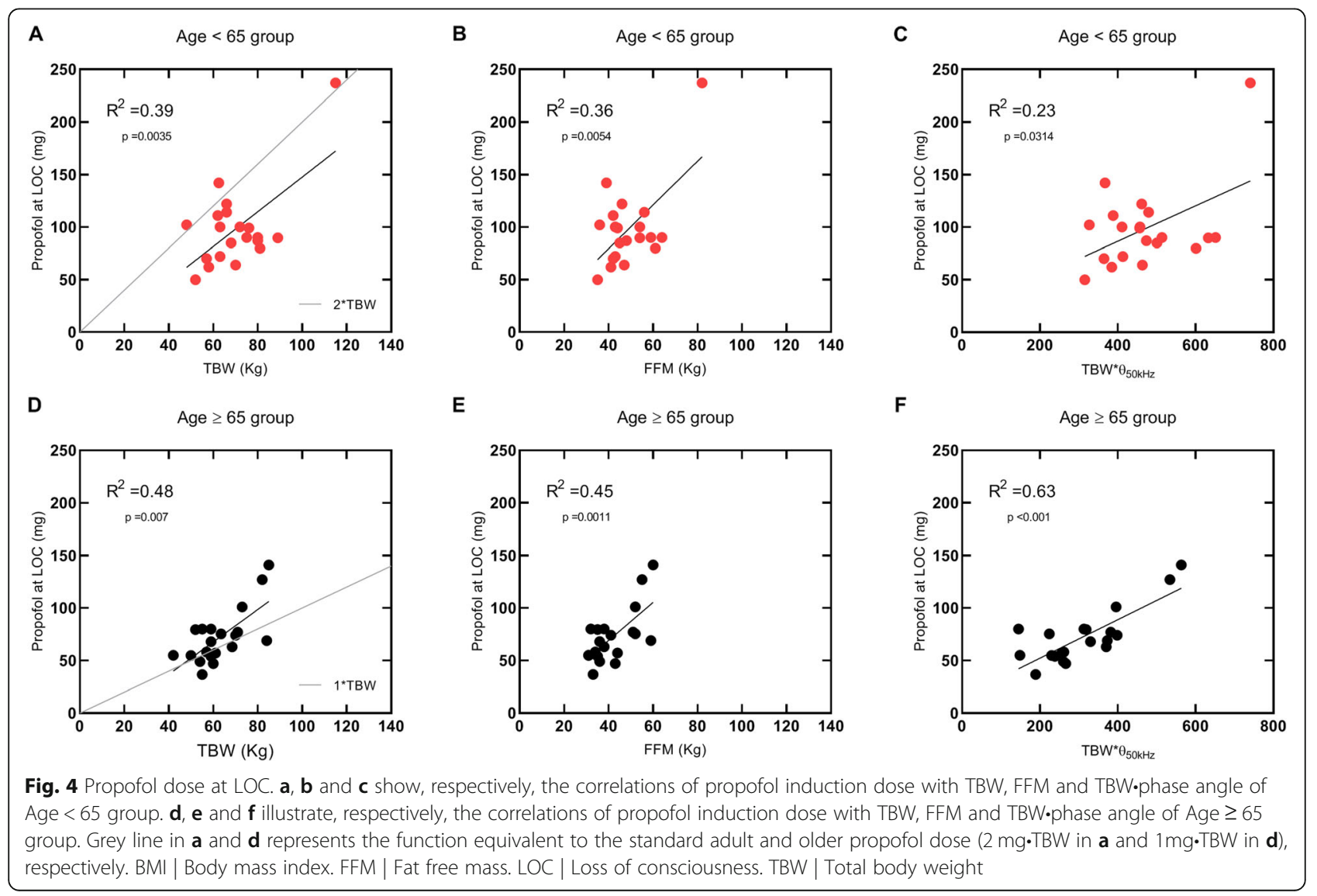


an easy and reliable tool to assess frailty in older patients. A multivariate analysis comparing adult and older healthy patients with adult and older frail patients is necessary to accurately determine the effect of frailty on propofol induction dose.

\section{Abbreviations}

ASA: American Society of Anesthesiology; BCM: Body composition monitor; BIA: Bioelectrical impedance analysis; BIS: Bispectral index; BMI: Body mass index; CFS: Clinical frailty scale; FFM: Fat free mass; FM: Fat mass; GC/ITMS: Gas chromatography/ion trap-mass spectrometry; LBW: Lean body weight; LOC: Loss of consciousness; MAP: Mean arterial pressure; STROBE: Strengthening the reporting of Observational studies in epidemiology; TBW: Total body weight

\section{Acknowledgments}

The authors thank Toxicological Laboratory, Department of Biological Sciences, Faculty of Pharmacy, University of Porto for technical cooperation in propofol plasma dosing

\section{Authors' contributions}

All authors designed the study, analyzed the data and contributed to manuscript preparation (drafting and revision). AA conducted the study protocol. All authors read and approved the final manuscript.

\section{Funding}

Financial support from the "Fundo para a Investigação e Desenvolvimento do Centro Hospitalar do Porto" is gratefully acknowledge. The medical technology and services company Medtronic ${ }^{\mathrm{TM}}$ provided BIS brain monitoring sensors. Fresenius Medical Care Portugal ${ }^{T M}$ made available BCM monitor during the study period.

None of the funding sources participated in the design of the study, collection, analysis and interpretation of data, or in writing of the manuscript.

\section{Availability of data and materials}

The datasets used and/or analyzed during the current study available from the corresponding author on reasonable request.

\section{Ethics approval and consent to participate}

This study was approved by the Ethical Committee of Centro Hospitalar do Porto, Porto, Portugal (IRB: N/REF.a 2015.221(183-DEFI/165-CES) and written informed consent was obtained from all subjects participating in the trial.

\section{Consent for publication}

Not applicable.

\section{Competing interests}

The authors declare that they have no competing interests.

\section{Author details}

'Serviço de Anestesiologia, Centro Hospitalar Universitário do Porto, Largo Prof. Abel Salazar, 4099-001 Porto, Portugal. ' ${ }^{2}$ Laboratory of Pharmacology, Faculty of Pharmacy, University of Coimbra, Pólo das Ciências da Saúde, Azinhaga de Santa Comba, 3000-548 Coimbra, Portugal. ${ }^{3}$ Department of Biomedicine, Unit of Pharmacology and Therapeutics, Faculty of Medicine, University of Porto, Alameda Prof. Hernâni Monteiro, 4200-319 Porto, Portugal.

Received: 19 February 2019 Accepted: 24 September 2019 Published online: 11 October 2019

\section{References}

1. Griffiths R, Beech F, Brown A, Dhesi J, Foo I, Goodall J, Harrop-Griffiths W, Jameson J, Love N, Pappenheim K, et al. Peri-operative care of the elderly 2014: Association of Anaesthetists of Great Britain and Ireland. Anaesthesia. 2014;69(Suppl 1):81-98.

2. Amrock $L G$, Deiner $\mathrm{S}$. The implication of frailty on preoperative risk assessment. Curr Opin Anaesthesiol. 2014;27(3):330-5.
3. McLachlan AJ, Bath S, Naganathan V, Hilmer SN, Le Couteur DG, Gibson SJ, Blyth FM. Clinical pharmacology of analgesic medicines in older people: impact of frailty and cognitive impairment. Br J Clin Pharmacol. 2011;71(3):351-64.

4. Rivera $R$, Antognini JF. Perioperative drug therapy in elderly patients. Anesthesiology. 2009;110(5):1176-81.

5. Akhtar S, Ramani R. Geriatric pharmacology. Anesthesiol Clin. 2015;33(3):457-69.

6. Klotz U. Pharmacokinetics and drug metabolism in the elderly. Drug Metab Rev. 2009:41(2):67-76.

7. Phillips AT, Deiner $\mathrm{S}$, Mo Lin H, Andreopoulos E, Silverstein J, Levin MA. Propofol use in the elderly population: prevalence of overdose and association with 30-day mortality. Clin Ther. 2015;37(12):2676-85.

8. Ingrande J, Brodsky JB, Lemmens HJM. Lean body weight scalar for the anesthetic induction dose of propofol in morbidly obese subjects. Anesth Analg. 2011;113(1):57-62.

9. Mitchell SJ, Kirkpatrick CM, Le Couteur DG, Naganathan V, Sambrook PN, Seibel MJ, Blyth FM, Waite LM, Handelsman DJ, Cumming RG, et al. Estimation of lean body weight in older community-dwelling men. $\mathrm{Br} J$ Clin Pharmacol. 2010;69(2):118-27.

10. Gupta D, Lammersfeld CA, Vashi PG, King J, Dahlk SL, Grutsch JF, Lis CG. Bioelectrical impedance phase angle as a prognostic indicator in breast cancer. BMC Cancer. 2008;8:249.

11. Barbosa-Silva MC, Barros AJ. Bioelectrical impedance analysis in clinical practice: a new perspective on its use beyond body composition equations. Curr Opin Clin Nutr Metab Care. 2005;8(3):311-7.

12. Mullie L, Obrand A, Bendayan M, Trnkus A, Ouimet M-C, Moss E, ChenTournoux A, Rudski LG, Afilalo J. Phase angle as a biomarker for frailty and postoperative mortality: the BICS study. J Am Heart Assoc. 2018;7(17):e008721.

13. Stapel SN, Looijaard WGPM, Dekker IM, Girbes ARJ, Weijs PJM, Oudemansvan Straaten HM. Bioelectrical impedance analysis-derived phase angle at admission as a predictor of 90-day mortality in intensive care patients. Eur J Clin Nutr. 2018;72(7):1019-25.

14. Goswami PN, Munna K, Moinuddin. Bioelectrical impedance analysis: phase angle - an independent predictive health marker and its clinical applications. Berlin, Heidelberg: Springer Berlin Heidelberg; 2007. p. 321-4.

15. Wilhelm-Leen ER, Hall YN, Horwitz RI, Chertow GM. Phase angle, frailty and mortality in older adults. J Gen Intern Med. 2014;29(1):147-54

16. Araujo AM, Machado HS, Falcao AC, Soares-da-Silva P. Reliability of bodyweight scalars on the assessment of propofol induction dose in obese patients. Acta Anaesthesiol Scand. 2018;62(4):464-73.

17. BCM - Body Composition Monitor. http://www.bcm-fresenius.com/. Accessed Sept 2017

18. Bosy-Westphal A, Danielzik S, Dorhofer RP, Later W, Wiese S, Muller MJ. Phase angle from bioelectrical impedance analysis: population reference values by age, sex, and body mass index. JPEN J Parenter Enteral Nutr. 2006;30(4):309-16.

19. Kyle UG, Bosaeus I, De Lorenzo AD, Deurenberg P, Elia M, Gomez JM, Heitmann BL, Kent-Smith L, Melchior JC, Pirlich M, et al. Bioelectrical impedance analysis--part I: review of principles and methods. Clin Nutr. 2004;23(5):1226-43.

20. Kyle UG, Genton L, Karsegard L, Slosman DO, Pichard C. Single prediction equation for bioelectrical impedance analysis in adults aged 20--94 years. Nutrition. 2001;17(3):248-53.

21. Roubenoff R, Baumgartner RN, Harris TB, Dallal GE, Hannan MT, Economos CD, Stauber PM, Wilson PW, Kiel DP. Application of bioelectrical impedance analysis to elderly populations. J Gerontol A Biol Sci Med Sci. 1997;52(3):M129-36.

22. Rockwood K, Song X, MacKnight C, Bergman H, Hogan DB, McDowell I, Mitnitski A. A global clinical measure of fitness and frailty in elderly people. CMAJ. 2005;173(5):489-95.

23. Minto CF, Schnider TW, Shafer SL. Pharmacokinetics and pharmacodynamics of remifentanil. II. Model application. Anesthesiology. 1997;86(1):24-33.

24. Campos SMJ, Antunes L, Branco PS, Ferreira LM, Pinho PG. Simultaneous quantification of propofol and its non-conjugated metabolites in several biological matrices using gas chromatography/ion trap - mass spectrometry method. J Anal Bioanal Tech. 2014;5(3):195.

25. Janmahasatian S, Duffull SB, Ash S, Ward LC, Byrne NM, Green B. Quantification of lean bodyweight. Clin Pharmacokinet. 2005;44(10):1051-65.

26. Iannuzzi M, lannuzzi E, Rossi F, Berrino L, Chiefari M. Relationship between bispectral index, electroencephalographic state entropy and effect-site EC50 for propofol at different clinical endpoints. Br J Anaesth. 2005;94(4):492-5.

27. Kazama T, Ikeda K, Morita K, Kikura M, Ikeda T, Kurita T, Sato S. Investigation of effective anesthesia induction doses using a wide range of infusion rates with undiluted and diluted propofol. Anesthesiology. 2000;92(4):1017-28. 
28. Doufas AG, Bakhshandeh M, Bjorksten AR, Shafer SL, Sessler DI. Induction speed is not a determinant of propofol pharmacodynamics. Anesthesiology. 2004;101(5):1112-21.

29. Struys M, Versichelen L, Thas O, Herregods L, Rolly G. Comparison of computer-controlled administration of propofol with two manually controlled infusion techniques. Anaesthesia. 1997;52(1):41-50.

30. Chan WW, Chung FF. Propofol infusion for induction and maintenance of anesthesia in elderly patients: recovery and hemodynamic profiles. J Clin Anesth. 1996;8(4):317-23.

31. Rather ZM, Rather MN, Afaq B, Farooq U, Ara Majid N. The effect of propofol when injected at different speeds for induction of general anesthesia: an observational study. Int J Clin Trials. 2018;5(2):7

32. Peacock JE, Lewis RP, Reilly CS, Nimmo WS. Effect of different rates of infusion of propofol for induction of anaesthesia in elderly patients. Br J Anaesth. 1990;65(3):346-52

33. Hardman JG, Hopkins PM, Struys MMRF. Oxford textbook of anaesthesia. Oxford University Press; 2017

34. Al-Rifai Z, Mulvey D. Principles of total intravenous anaesthesia: practical aspects of using total intravenous anaesthesia. BJA Educ. 2016;16(8):276-80.

35. Eleveld DJ, Colin P, Absalom AR, Struys MMRF. Pharmacokineticpharmacodynamic model for propofol for broad application in anaesthesia and sedation. Br J Anaesth. 2018:120(5):942-59.

36. Sessler DI, Sigl JC, Kelley SD, Chamoun NG, Manberg PJ, Saager L, Kurz A, Greenwald S. Hospital stay and mortality are increased in patients having a "triple low" of low blood pressure, low bispectral index, and low minimum alveolar concentration of volatile anesthesia. Anesthesiology. 2012:116(6):1195-203.

37. Vuyk J. TCl: supplementation and drug interactions. Anaesthesia. 1998; 53(Suppl 1):35-41.

38. Milne SE, Kenny GN, Schraag S. Propofol sparing effect of remifentanil using closed-loop anaesthesia. Br J Anaesth. 2003;90(5):623-9.

39. Smith C, McEwan Al, Jhaveri R, Wilkinson M, Goodman D, Smith LR, Canada AT, Glass PS. The interaction of fentanyl on the Cp50 of propofol for loss of consciousness and skin incision. Anesthesiology. 1994:81(4):820-8 discussion 826A.

40. Kazama T, Ikeda K, Morita K. Reduction by fentanyl of the Cp50 values of propofol and hemodynamic responses to various noxious stimuli. Anesthesiology. 1997;87(2):213-27.

\section{Publisher's Note}

Springer Nature remains neutral with regard to jurisdictional claims in published maps and institutional affiliations.

Ready to submit your research? Choose BMC and benefit from:

- fast, convenient online submission

- thorough peer review by experienced researchers in your field

- rapid publication on acceptance

- support for research data, including large and complex data types

- gold Open Access which fosters wider collaboration and increased citations

- maximum visibility for your research: over $100 \mathrm{M}$ website views per year

At $\mathrm{BMC}$, research is always in progress.

Learn more biomedcentral.com/submissions 